\title{
Hepatic Metabolic, Inflammatory, and Stress-Related Gene Expression in Growing Mice Consuming a Low Dose of Trans-10, cis-12-Conjugated Linoleic Acid
}

\author{
Jing Li, ${ }^{1}$ Srikant Viswanadha, ${ }^{2,3}$ and Juan J. Loor ${ }^{1}$ \\ ${ }^{1}$ Division of Nutritional Sciences, Mammalian NutriPhysioGenomics, Department of Animal Sciences, University of Illinois, \\ 1207 West Gregory Drive, Urbana IL61801, USA \\ ${ }^{2}$ Dairy Science Department, Virginia Tech, Blacksburg, VA 24061, USA \\ ${ }^{3}$ Incozen Therapeutics Pvt. Ltd, "Spectrum” Discovery Zone, SP Biotech Park-Phase 1, Turkapally Mandal, Hyderabad 500078, India
}

Correspondence should be addressed to Juan J. Loor, jloor@illinois.edu

Received 28 April 2012; Revised 24 June 2012; Accepted 27 June 2012

Academic Editor: Gerhard M. Kostner

Copyright () 2012 Jing Li et al. This is an open access article distributed under the Creative Commons Attribution License, which permits unrestricted use, distribution, and reproduction in any medium, provided the original work is properly cited.

\begin{abstract}
Dietary trans-10, cis-12-conjugated linoleic acid (trans-10, cis-12-CLA) fed to obese and nonobese rodents reduces body fat but leads to greater liver mass due to steatosis. The molecular mechanisms accompanying such responses remain largely unknown. Our study investigated the effects of chronic low trans-10, cis-12-CLA supplementation on hepatic expression of 39 genes related to metabolism, inflammation, and stress in growing mice. Feeding a diet supplemented with $0.3 \%$ trans-10, cis-12-CLA (wt/wt basis) for 6 weeks increased liver mass and concentration of long-chain fatty acids (LCFAs) in liver, while adipose tissue mass decreased markedly. These changes were accompanied by greater expression of genes involved in LCFA uptake (Cd36), lipogenesis, and triacylglycerol synthesis (Acaca, Gpam, Scd, Pck1, Plin2). Expression of these genes was in line with upregulation of the lipogenic transcription factor Srebf1. Unlike previous studies where higher $>0.50 \%$ of the diet) doses of trans-10, cis-12-CLA were fed, we found greater expression of genes associated with VLDL assembly/secretion (Mttp, Cideb), ketogenesis (Hmgcs2, Bdh1), and LCFA oxidation (Acox1, Pdk4) in response to trans-10, cis-12-CLA. Dietary CLA, however, did not affect inflammation- and stress-related genes. Results suggested that a chronic low dose of dietary CLA increases liver mass and lipid accumulation due to activation of lipogenesis and insufficient induction of LCFA oxidation and VLDL assembly/secretion.
\end{abstract}

\section{Introduction}

Conjugated linoleic acid (CLA) refers to a group of conjugated octadecadienoic acid isomers derived from linoleic acid (LA), a long-chain fatty acid (LCFA) that contains 18 carbons and 2 double bonds [1]. Antilipogenic effects of dietary CLA mixtures with a $1: 1$ ratio of trans-10, cis-12-CLA and cis-9, trans-11-CLA were initially observed in several lines of mice, and later work using purified isomer preparations clearly showed that trans-10, cis-12-CLA was responsible for delipidation [2, 3] (summarized in Table 1). Studies also have revealed unfavorable metabolic effects of trans-10, cis12-CLA associated with an increased oxidative stress and inflammation [4] often coupled with hepatic steatosis [59]. As trans-10, cis-12-CLA supplementation reduces the amount of adipose tissue, several studies suggest that much of the increased liver mass may be explained by accumulation of lipid $[10,11]$ derived from breakdown of adipose tissue stores $[12,13]$.

Despite the clear deleterious effects observed in rodents, the European Food Safety authority after an evaluation of the available data concluded that consumption of $3.5 \mathrm{~g}$ CLA (or $4.5 \mathrm{~g}$ product/d) from a commercial product containing equal proportions of trans-10, cis-12-CLA and cis-9, trans11-CLA was not deleterious to health [14]. However, at the molecular level, hepatic steatosis in rodents due to trans-10, cis-12-CLA at $\geq 0.5 \%$ of the diet has been linked to alterations in the expression of genes associated with energy expenditure, apoptosis, fatty acid oxidation, lipolysis, differentiation, and lipogenesis $[1,15]$. Therefore, it is likely that sustained supplementation of the above amount, which is much greater 
TABLE 1: Summary of the changes in liver mass, liver TG, and adipose tissue mass observed in previous mouse studies feeding different levels of trans-10, cis-12-CLA compared with feeding linoleic acid (LA) or oleic acid (as canola oil).

\begin{tabular}{|c|c|c|c|c|c|}
\hline \multirow{2}{*}{ Reference } & \multirow{2}{*}{ Dose } & \multirow{2}{*}{ Duration } & \multicolumn{3}{|c|}{ trans-10, cis-12 CLA response ${ }^{2}$} \\
\hline & & & Liver mass & Liver TG/fat & Adipose mass \\
\hline Clément et al. (2002) [5] & $0.4 \%$ & 4 weeks & 3.1 fold $\uparrow$ & N.A ${ }^{1}$ & $80 \% \downarrow$ \\
\hline Halade et al. (2009) [53] & $0.5 \%$ & 0.5 year & $50 \% \uparrow$ & N.A & $73 \% \downarrow$ \\
\hline Degrace et al. (2003) [12] & $10 \mathrm{~g}$ & 4 weeks & $60 \% \uparrow$ & $655 \% \uparrow$ & $83 \% \downarrow$ \\
\hline Kelley et al. (2004) [7] & $0.5 \%$ & 8 weeks & N.A & 5 fold $\uparrow$ & N.A \\
\hline House et al. (2005) [10] & $1 \%$ & 2 weeks & $33 \% \uparrow$ & $61 \% \uparrow$ & $58 \% \downarrow$ \\
\hline Warren et al. (2003) [54] & $0.5 \%$ & 8 weeks & $98 \% \uparrow$ & $427 \% \uparrow$ & $59 \% \downarrow$ \\
\hline Degrace et al. (2004) [13] & $1 \%$ & 4 weeks & $80 \% \uparrow$ & $646 \% \uparrow$ & $85 \% \downarrow$ \\
\hline
\end{tabular}

${ }^{1}$ Not available.

${ }^{2}$ Percentage $=[$ Wt of CLA-fed Mice - Wt of LA or canola oil-fed Mice $] /[$ Wt of LA or CO-fed Mice $] \times 100$.

than the $3.1 \mathrm{mg}$ CLA/kg body weight estimated previously [16], has the potential to alter tissue expression of genes in pathways of metabolism, inflammation, and stress as has been shown in rodent studies.

To our knowledge there are no published studies dealing with the hepatic transcriptome in response to low chronic dietary trans-10, cis-12-CLA supplementation. Our general hypothesis was that long-term increases in liver mass in response to dietary trans-10, cis-12-CLA at low doses would be associated with alterations in mRNA abundance of lipogenic, fatty acid oxidation, and inflammatory genes. Specific objectives were to measure mRNA abundance of genes encoding proteins required for LCFA uptake, LCFA oxidation, de novo LCFA synthesis, lipolysis, lipogenesis, ketogenesis, inflammation, stress response, transcriptional regulation of lipogenesis, and lipid droplet formation.

\section{Materials and Methods}

2.1. Animals, Diets, Sampling, and Fatty Acid Analysis. All experiments were approved by the Institutional Animal Care and Use Committee (IACUC) at Virginia Tech. Male CD1 mice from Harlan (Madison, Wis, USA), 3 to 4 weeks of age, were divided into two experimental groups of ten mice each. Mice were housed individually with access to food and water at all times. A 12-h light/12-h dark cycle was maintained throughout the study. For $7 \mathrm{~d}$ before the start of the study, all mice were fed Harlan Teklad (Global Rodent Diet, $18 \%$ protein, $5 \%$ fat; Harlan, Madison, WI, USA) with $3 \%(\mathrm{w} / \mathrm{w})$ high-oleic sunflower oil added. On day 1 of the study, mice were randomly assigned to receive diets containing 3.0\% high-oleic sunflower (control) or $2.70 \%$ high-oleic sunflower oil $+0.30 \%$ trans-10, cis-12-CLA. The free FA form of trans-10, cis-12-CLA ( $>95 \%$ purity) was obtained from Natural Lipids (Hovdebygda, Norway). Mice were fed daily at 1600 hours. At the end of weeks 2 and 6 , five mice per dietary treatment were anesthetized using Metofane (Pitman-Moore, Inc., Washington Crossing, NJ, USA) prior to cervical dislocation. The liver was removed, rinsed with diethylpyrocarbonate (Sigma, St. Louis, MO, USA) in distilled water $(1: 1000, \mathrm{v} / \mathrm{v})$, and weighed. A portion of liver was frozen in liquid nitrogen and later stored at $-80^{\circ} \mathrm{C}$ prior to RNA extraction and gene expression analysis.

Total LCFA in liver were extracted as described previously [17]. Undecenoic acid (Nu-Check Prep, Inc., Elysian, Min, USA), added to extracted lipids prior to formation of fatty acid methyl esters (FAME) [18], served as an internal standard. Using an Agilent $6890 \mathrm{~N}$ gas chromatograph equipped with a flame ionization detector (Agilent Technologies, Palo Alto, Calif, USA), FAME were separated with a $100 \mathrm{~m} \times$ $0.25 \mathrm{~mm}$ i.d. $(0.2 \mu \mathrm{m}$ film thickness) CP-Sil 88 column (Varian, Lake Forest, Calif, USA) protected by a $2.5 \mathrm{~m} \times$ $0.25 \mathrm{~mm}$ i.d. fused silica retention gap. Ultrapure hydrogen at constant pressure was the carrier gas. Pure methyl ester standards (Nu-Check Prep, Inc., Pa, USA) were used for identification and quantification of sample FA [17].

2.2. Additional Materials and Methods. Specific details of RNA extraction and quantitative real-time RT-PCR (qPCR) are reported in additional file 1 (supplementary material). qPCR performance, primer features, and sequencing are reported in Tables S1-S4 (additional file 1), (see Supplementary material available online at doi:10.1155/2012/571281). Results of internal control gene (ICG) evaluation are shown in Figure S1 (additional file 1).

2.3. Statistical Analysis. Data were analyzed as a completely randomized design with a factorial arrangement of treatments using the MIXED procedure of SAS (Windows version 9.1, Cary, NC, USA). Normalized gene expression data using the geometric mean of the top 4 most-stable ICG (Figure S1, additional file 1) were log-transformed prior to statistical analysis. The model for gene expression and liver LCFA profiles included the fixed effects of dietary treatment $(0 \%$ or $0.30 \%$ CLA), time (week 2 and 6), and the interaction of dietary treatment $x$ time. Mouse within dietary treatment $x$ time was the random effect. Least-squares means \pm standard error of the means (SEM), (combined observations for weeks 2 and 6 ) are presented in the tables.

\section{Results}

3.1. Tissue Weight. There was no difference in final live body weight between treatments, and the average was $37.1 \mathrm{~g}$ 
TABLE 2: Live body weight and weights of selected tissues and carcass in mice fed trans-10, cis-12-CLA (CLA).

\begin{tabular}{|c|c|c|c|c|}
\hline & & & & \\
\hline & Control & CLA & SEM & $P$ \\
\hline Body weight (g) & 38.6 & 35.6 & 1.6 & 0.24 \\
\hline Liver $(\mathrm{g})$ & $1.99^{\mathrm{b}}$ & $2.36^{\mathrm{a}}$ & 0.12 & 0.04 \\
\hline Epididymal adipose (g) & $0.91^{\mathrm{a}}$ & $0.70^{\mathrm{b}}$ & 0.04 & 0.01 \\
\hline Carcass $(\mathrm{g})$ & $14.0^{\mathrm{a}}$ & $12.8^{\mathrm{b}}$ & 0.32 & 0.01 \\
\hline
\end{tabular}

${ }^{\mathrm{a}, \mathrm{b}}$ Means with different superscripts differ $(P \leq 0.05)$.

SEM: the largest standard error of the mean is shown.

TABLE 3: Long-chain fatty acid concentrations in liver from mice fed control or the control supplemented with trans-10, cis-12-CLA (CLA). There were few significant interactions of treatment $\times$ time. Therefore, the results are presented according to main effects (treatment and time).

\begin{tabular}{|c|c|c|c|c|c|}
\hline \multirow{2}{*}{ Item } & \multicolumn{2}{|c|}{ Treatment } & \multicolumn{2}{|c|}{ Time } & \multirow[t]{2}{*}{ SEM } \\
\hline & Control & CLA & Week 2 & Week 6 & \\
\hline Total fatty acids, $\mu \mathrm{g} / \mathrm{mg}$ dry liver & $42.5^{\mathrm{b}}$ & $60.3^{\mathrm{a}}$ & $41.0^{\mathrm{b}}$ & $61.7^{\mathrm{a}}$ & 4.5 \\
\hline $16: 0$ & 22.5 & 24.1 & $28.6^{\mathrm{a}}$ & $17.9^{\mathrm{b}}$ & 1.2 \\
\hline $18: 0^{3}$ & $19.6^{\mathrm{a}}$ & $14.0^{\mathrm{b}}$ & $20.9^{\mathrm{a}}$ & $12.7^{\mathrm{b}}$ & 1.1 \\
\hline cis-9-18: 1 & $20.1^{\mathrm{b}}$ & $24.4^{\mathrm{a}}$ & $24.4^{\mathrm{a}}$ & $20.2^{\mathrm{b}}$ & 1.3 \\
\hline trans-10-18: 1 & $0.02^{\mathrm{b}}$ & $0.05^{\mathrm{a}}$ & $0.05^{\mathrm{a}}$ & $0.02^{\mathrm{b}}$ & 0.01 \\
\hline trans-11-18: 1 & 0.07 & 0.06 & 0.07 & 0.05 & 0.01 \\
\hline cis-9,cis-12-18: 2 & 18.0 & 19.2 & $13.5^{\mathrm{b}}$ & $23.7^{\mathrm{a}}$ & 1.4 \\
\hline cis-9,cis-12,cis-15-18: 3 & 0.60 & 0.56 & $0.68^{\mathrm{a}}$ & $0.48^{\mathrm{b}}$ & 0.07 \\
\hline \multicolumn{6}{|l|}{ CLA isomers } \\
\hline cis-9,trans-11-18: 2 & 0.01 & 0.03 & 0.03 & 0.02 & 0.01 \\
\hline trans-10,cis-12-18: $2^{1}$ & $<0.00^{\mathrm{b}}$ & $0.30^{\mathrm{a}}$ & $0.11^{\mathrm{b}}$ & $0.19^{a}$ & 0.02 \\
\hline Total $^{1}$ & $0.13^{\mathrm{b}}$ & $0.46^{\mathrm{a}}$ & 0.29 & 0.30 & 0.02 \\
\hline $20: 4 n-6$ & 8.3 & 6.1 & $3.0^{\mathrm{b}}$ & $11.4^{\mathrm{a}}$ & 0.9 \\
\hline $22: 6 n-3$ & 4.1 & 3.4 & $1.0^{\mathrm{b}}$ & $6.5^{\mathrm{a}}$ & 0.6 \\
\hline Total 20-carbon & 14.2 & 11.4 & $5.3^{\mathrm{b}}$ & $20.2^{\mathrm{a}}$ & 1.5 \\
\hline
\end{tabular}

${ }^{\mathrm{a}, \mathrm{b}}$ Means within each main effect (treatment and time) with different superscripts differ $(P \leq 0.05)$.

SEM: the largest standard error of the mean is shown.

${ }^{1}$ Significant treatment $\times$ time.

(Table 2). Liver weight was $\sim 19 \%$ greater in mice fed CLA and averaged $2.36 \mathrm{~g}$ versus $1.99 \mathrm{~g}$ in controls. In contrast, the weight of epididymal adipose tissue was $23 \%$ lower in CLAfed mice compared with controls, that is, $0.70 \mathrm{~g}$ versus $0.91 \mathrm{~g}$. Carcass weight was lower in CLA-fed mice compared with controls, averaging $12.8 \mathrm{~g}$ versus $14 \mathrm{~g}$.

3.2. Long-Chain Fatty Acid Concentration in Liver. The total concentration of LCFA in mice fed CLA increased by $~ 42 \%$ and averaged $60.3 \mu \mathrm{g} / \mathrm{mg}$ dry liver tissue versus $42.5 \mu \mathrm{g} / \mathrm{mg}$ (Table 3). There was an overall increase in LCFA concentration over time regardless of treatment, with concentration averaging $41 \mu \mathrm{g} / \mathrm{mg}$ at week 2 and increasing to $61.7 \mu \mathrm{g} / \mathrm{mg}$ at week 6. The concentration of 18:0 was lower in mice fed CLA (14\% versus 19.6\%), and it decreased markedly regardless of treatment between week 2 and $6(20.9 \%$ to $12.7 \%)$. The concentration of cis $9-18: 1$, the product of $18: 0$ desaturation, was greater in mice fed CLA $(24.4 \%$ versus $20.1 \%)$ and also decreased between week 2 and 6 (24.4\% to $20.2 \%$ ). As expected, the concentration of trans-10, cis-12CLA was greater in mice fed CLA $(0.30 \%$ versus $<0.00 \%)$ and also the concentration of trans-10-18:1 in those mice was greater $(0.05 \%$ versus $0.02 \%)$ relative to controls. Overall, the concentration of cis-9, cis-12-18:2, 20:4n-6, and 22:6n3 increased between week 2 and 6 regardless of treatment; whereas concentration of cis-9,cis-12,cis-15-18:3 decreased over the same time frame regardless of treatment.

3.3. Markers of Fatty Acid Uptake in Liver. The expression of $C d 36$ was greater $($ CLA $=1.11$ versus control $=-1.47 ; P=$ 0.001; Table 4) with trans-10, cis-12-CLA and there was no change due to treatment for Slc27a2 expression.

3.4. Lipogenesis and TG Synthesis. We observed that Acaca $(\mathrm{CLA}=0.72$ versus control $=0.22)$ and $S c d($ CLA $=$ 0.05 versus control $=-0.92$ ) expression was upregulated in response to trans-10, cis-12-CLA. Among the genes associated with TG synthesis, we observed upregulation of Gpam in mice fed trans-10, cis-12-CLA (CLA $=0.44$ versus control $=-0.31$, but the expression of Dgat1 and Dgat2 did not differ. Dietary CLA upregulated Pckl (CLA $=-0.29$ versus control $=-1.74)$ and also the lipid droplet-associated protein Plin2 $($ CLA $=0.40$ versus control $=-0.43)$. 
TABLE 4: Hepatic expression of genes related to LCFA uptake, lipogenesis, TG synthesis, lipoprotein synthesis, and transcription regulation in mice fed control or the control supplemented with trans-10, cis-12-CLA. There were no significant interactions of treatment $\times$ time. Therefore, the results are presented according to main effects (treatment and time).

\begin{tabular}{|c|c|c|c|c|c|}
\hline \multirow{2}{*}{ Gene } & \multicolumn{2}{|c|}{ Treatment } & \multicolumn{2}{|c|}{ Time } & \multirow{2}{*}{ SEM } \\
\hline & Control & CLA & Week 2 & Week 6 & \\
\hline \multicolumn{6}{|c|}{ Fatty acid uptake } \\
\hline$C d 36$ & $-1.47^{\mathrm{a}}$ & $1.11^{\mathrm{b}}$ & -0.01 & -0.35 & 0.55 \\
\hline Slc27a2 & -0.23 & -0.04 & -0.07 & -0.20 & 0.18 \\
\hline \multicolumn{6}{|c|}{ De novo synthesis and desaturation } \\
\hline Acaca & $0.22^{\mathrm{a}}$ & $0.72^{\mathrm{b}}$ & 0.42 & 0.51 & 0.11 \\
\hline Scd & $-0.92^{\mathrm{a}}$ & $0.05^{\mathrm{b}}$ & -0.50 & -0.37 & 0.19 \\
\hline \multicolumn{6}{|c|}{ TG and lipid droplet synthesis } \\
\hline Dgat1 & -0.02 & 0.30 & 0.23 & 0.05 & 0.17 \\
\hline Dgat2 & 0.03 & 0.25 & 0.26 & 0.02 & 0.15 \\
\hline Gpam & $-0.31^{\mathrm{a}}$ & $0.44^{\mathrm{b}}$ & 0.13 & 0.004 & 0.17 \\
\hline Pck1 & $-1.74^{\mathrm{a}}$ & $-0.29^{\mathrm{b}}$ & -0.80 & -1.24 & 0.62 \\
\hline Plin2 & $-0.43^{\mathrm{a}}$ & $0.40^{\mathrm{b}}$ & -0.01 & -0.02 & 0.18 \\
\hline \multicolumn{6}{|c|}{ Transcription regulation } \\
\hline Chrebp & -0.22 & -0.17 & -0.19 & -0.19 & 0.08 \\
\hline Srebf1 & $-0.22^{\mathrm{a}}$ & $0.14^{\mathrm{b}}$ & 0.04 & -0.11 & 0.11 \\
\hline \multicolumn{6}{|c|}{ VLDL synthesis } \\
\hline Apob & -0.33 & -0.05 & -0.09 & -0.29 & 0.19 \\
\hline Cideb & $-1.13^{\mathrm{a}}$ & $-0.04^{\mathrm{b}}$ & -0.35 & -0.81 & 0.50 \\
\hline Mttp & $-0.37^{\mathrm{a}}$ & $0.14^{\mathrm{b}}$ & 0.002 & -0.22 & 0.17 \\
\hline \multicolumn{6}{|c|}{ Carbohydrate Metabolism } \\
\hline Gck & -0.45 & -0.49 & -0.31 & -0.63 & 0.28 \\
\hline$P c$ & -0.31 & -0.08 & -0.08 & -0.32 & 0.28 \\
\hline Slc2a1 & -0.07 & 0.21 & 0.18 & -0.04 & 0.14 \\
\hline \multicolumn{6}{|l|}{ Lipolysis } \\
\hline Lipc & -0.95 & -0.20 & -0.15 & -1.00 & 0.54 \\
\hline Pnpla2 & -0.04 & 0.14 & 0.24 & -0.13 & 0.24 \\
\hline
\end{tabular}

${ }_{\mathrm{a}, \mathrm{b}}$ Means within each main effect (treatment and time) with different superscripts differ $(P \leq 0.05)$.

SEM: the largest standard error of the mean is shown.

3.5. Transcription Regulation and Lipogenesis and TG Synthesis. Although the expression of glucose-regulated transcription factor Chrebp did not differ between treatments, we observed that Srebf1 expression in mice fed trans-10, cis-12CLA was upregulated $(\mathrm{CLA}=0.14$ versus control $=-0.22)$.

3.6. VLDL Assembly and Secretion. We observed significant upregulation of Mttp $(\mathrm{CLA}=0.14$ versus control $=-0.37)$ and Cideb $(\mathrm{CLA}=-0.04$ versus control $=-1.13$ ) in mice fed trans-10, cis-12-CLA, but expression of Apob did not differ.

3.7. Carbohydrate Metabolism. We observed no treatment effects in the expression of genes associated with glucose transport (Slc2a1), glycolysis (Gck), and gluconeogenesis $(P c)$.

3.8. Lipolysis. We observed no treatment effects in the expression of the lipolytic genes Lipc and Pnpla2.

3.9. Ppard, Lipid Catabolism, and Energy Metabolism. We did not observe differences in expression of Ppara but expression of its targets $P d k 4$ (CLA $=0.47$ versus control $=-1.85), A c o x 1$ $(\mathrm{CLA}=0.13$ versus control $=-0.22)$, and Ucp2 $(\mathrm{CLA}=0.15$ versus control $=-0.31$ ) was upregulated (Table 5). Another well-established Ppara target such Cpt1a did not differ due to CLA but the expression of the ketogenic regulator $\mathrm{Hmgcs} 2$ $(\mathrm{CLA}=0.13$ versus control $=-0.16$ and enzyme $B d h 1$ $(\mathrm{CLA}=0.13$ versus control $=-0.20)$ was upregulated with CLA.

3.10. Inflammation and Stress Response. The expression of one gene associated with inflammation (Saa1) and 8 genes associated with intracellular stress (Angptl3, Angptl4, Atf6, Ddit3, Eif2ak3, Fgfr2, Hspa1b, Xbp1) did not differ due to treatments (Table 6).

\section{Discussion}

Several studies have shown that trans-10, cis-12-CLA at $\geq 0.5 \%$ of the diet reduced adipose mass and increased liver mass (summarized in Table 1). In the present study, we fed a low dose of trans-10, cis-12-CLA that may be 
TABLE 5: Hepatic expression of genes related to lipid catabolism in mice fed control or the control supplemented with trans-10, cis-12-CLA (CLA). There were no significant interactions of treatment $\times$ time. Therefore, the results are presented according to main effects (treatment and time).

\begin{tabular}{|c|c|c|c|c|c|}
\hline \multirow{2}{*}{ Gene } & \multicolumn{2}{|c|}{ Treatment } & \multicolumn{2}{|c|}{ Time } & \multirow{2}{*}{ SEM } \\
\hline & Control & CLA & Week 2 & Week 6 & \\
\hline \multicolumn{6}{|c|}{ Fatty acid oxidation and energy metabolism } \\
\hline Aacs & -0.21 & -0.29 & -0.26 & -0.25 & 0.31 \\
\hline Acoxl & $-0.22^{\mathrm{a}}$ & $0.13^{\mathrm{b}}$ & -0.08 & -0.003 & 0.14 \\
\hline$B d h 1$ & $-0.20^{\mathrm{a}}$ & $0.13^{\mathrm{b}}$ & 0.06 & -0.12 & 0.12 \\
\hline Cpt1a & -0.43 & -0.32 & -0.36 & -0.39 & 0.14 \\
\hline Insig1 & -0.79 & 0.35 & -0.23 & -0.20 & 0.45 \\
\hline Mlycd & 0.001 & -0.17 & -0.07 & -0.11 & 0.10 \\
\hline$P d k 4$ & $-1.85^{\mathrm{a}}$ & $0.47^{\mathrm{b}}$ & -0.81 & -0.57 & 0.50 \\
\hline$U c p 2$ & $-0.31^{\mathrm{a}}$ & $0.15^{\mathrm{b}}$ & -0.04 & -0.11 & 0.10 \\
\hline Hmgcs2 & $-0.16^{\mathrm{a}}$ & $0.13^{\mathrm{b}}$ & $0.10^{\mathrm{a}}$ & $-0.13^{\mathrm{b}}$ & 0.11 \\
\hline \multicolumn{6}{|c|}{ Transcription regulation } \\
\hline Ppar $\alpha$ & -0.33 & -0.19 & -0.23 & -0.30 & 0.12 \\
\hline
\end{tabular}

${ }_{\mathrm{a}, \mathrm{b}}$ Means within each main effect (treatment and time) with different superscripts differ $(P \leq 0.05)$.

SEM: the largest standard error of the mean is shown.

TABLE 6: Hepatic expression of genes related to inflammation and cellular stress in mice fed control or the control supplemented with trans10, cis-12-CLA (CLA). There were no significant interactions of treatment $\times$ time. Therefore, the results are presented according to main effects (treatment and time).

\begin{tabular}{|c|c|c|c|c|c|}
\hline \multirow{2}{*}{ Gene } & \multicolumn{2}{|c|}{ Treatment } & \multicolumn{2}{|c|}{ Time } & \multirow{2}{*}{ SEM } \\
\hline & Control & CLA & Week 2 & Week 6 & \\
\hline \multicolumn{6}{|c|}{ Inflammation } \\
\hline Saal & -0.50 & -0.21 & -0.17 & -0.54 & 0.31 \\
\hline \multicolumn{6}{|c|}{ Stress response } \\
\hline Angptl3 & -0.54 & 0.07 & -0.26 & -0.21 & 0.42 \\
\hline Angptl4 & 0.01 & -0.29 & -0.53 & 0.25 & 0.35 \\
\hline Atf6 & -0.27 & 0.17 & 0.16 & -0.26 & 0.46 \\
\hline Ddit3 & -0.25 & 0.37 & -0.11 & 0.24 & 0.30 \\
\hline Eif $2 a k 3$ & -0.55 & -0.10 & -0.32 & -0.32 & 0.49 \\
\hline Fgfr 2 & -0.09 & 0.19 & -0.58 & 0.68 & 0.49 \\
\hline Hspa1b & -1.04 & -0.54 & -0.91 & -0.67 & 0.62 \\
\hline$X b p 1$ & -1.15 & -0.55 & -0.46 & -1.23 & 0.63 \\
\hline
\end{tabular}

${ }_{\mathrm{a}, \mathrm{b}}$ Means within each main effect (treatment and time) with different superscripts differ $(P \leq 0.05)$.

SEM: the largest standard error of the mean is shown.

considered more physiologically relevant, compared with previous studies, from a nutritional standpoint to examine any potential links between adipose mass loss, liver mass, and expression of genes related to various aspects of lipid metabolism. Hepatic enlargement has been associated with a 3- to 7-fold increase in TG content (Table 1), and we also observed an increase in liver mass and accumulation of LCFA (Tables 2 and 3).

4.1. Trans-10, cis-12-CLA Increased Markers of Fatty Acid Uptake in Liver. Our results are in agreement with previous data showing two-fold greater hepatic LCFA content [7] and lower serum LCFA concentration in mice fed trans-10, cis12-CLA [13]. Therefore, upregulation of Cd36 expression with trans-10, cis-12-CLA allows for adipose tissue-derivedLCFA uptake into hepatocytes and, in fact, may represent a mechanism unique to this isomer because it has been shown in vitro that uptake of trans-10, cis-12-CLA in rat hepatocytes was $3 \mathrm{X}$ greater than for oleate [19]. Furthermore, a previous study showed not only a significant increase in hepatic Cd36 expression in mice fed trans-10, cis-12-CLA but also a significant association between $C d 36$ expression and the degree of hepatic steatosis [20]. Therefore, upregulation of Cd36 at low dietary trans-10, cis-12-CLA is part of the mechanism leading to increased hepatic fatty acid uptake and hepatic steatosis.

4.2. Trans-10, cis-12-CLA Stimulates Lipogenesis and TG Synthesis in Liver. Several authors have concluded that de novo fatty acid synthesis via acetyl-CoA carboxylase (Acaca) and fatty acid synthase (Fasn) may play a role in the onset of hepatic steatosis related to CLA supplementation [21, 22]. 
The upregulation of Acaca with CLA suggested that the liver was generating more malonyl-CoA which was then used for palmitic acid synthesis by the multifunctional enzyme Fasn. The numerically greater concentration of 16:0 in CLA-fed mice $(24.1 \%$ versus $22.5 \%)$ provides some support for such an effect. Ashwell et al. [15] and Kelley et al. [7] observed greater 16:0 in liver tissue of obese mice fed trans-10, cis-12CLA than those fed a linoleic acid or corn oil.

Stearoyl-CoA desaturase (Scd) is the rate-limiting enzyme involved in the synthesis of mono-unsaturated fatty acids (cis-9-16:1 or cis-9-18:1) from saturated fatty acids $(16: 0$ or $18: 0)$ [23]. Although not in the glycerol-3-phosphate pathway of TG synthesis, Scd plays an important role in the synthesis of TG [23]. The expression of the mouse Scd gene is regulated primarily at the level of transcription [24], and its expression in adipose tissue decreases as the trans-10, cis-12-CLA content of the diet increases [6]. The upregulation of $S c d$ we observed with CLA confirmed results from Guillén et al. [20] in mice. Furthermore, the upregulation of $S c d$ in our study correlated with the lower concentration of 18:0 (substrate) and greater concentration of cis9-18:1 (main product), (Table 3). Because a large number of studies have shown that trans-10, cis-12-CLA reduces body fat mass considerably, the upregulation of hepatic $S c d$ mRNA due to feeding trans-10, cis-12-CLA may be a response to handle the influx of 16:0 and 18:0 derived from adipose tissue lipolysis.

The initial reaction in the pathway of TG synthesis is catalyzed by glycerol-3-phosphate acyltransferase (Gpam) which resides in the outer mitochondrial membrane [25] and it is the first committed step in the synthesis of TG [25] via the glycerol phosphate pathway. In addition, Gpam is an enzyme that can determine the fate of LCFA between $\beta$ oxidation or glycerolipid synthesis [26]. Subsequent steps of TG synthesis are regulated by Dgat1 and Dgat2, while Pck1 provides a source of glycerol-3-phosphate during glyceroneogenesis [27]. Perilipin (Plin) proteins are vital for cytoplasmic lipid droplet (LD) formation [28]. In isolated hepatocytes, as well as livers from mice and humans, Plin2 levels are proportional to hepatic lipid content [29].

Our results for Gpam expression are contrary to a previous study which found that trans-10, cis-12-CLA did not change the hepatic expression of Gpam in mice [15]. The concerted upregulation of Acaca, Gpam, Pckl, and Plin2 could be taken as a mechanistic response to promote biosynthesis of TG and lipid droplet formation, for example, the upregulation of Acaca stimulates de novo FA synthesis, thus, generating more precursors (i.e., feed-forward effect) for TG synthesis leading to stimulation of both Gpam and Pck1 expression. In addition, Plin protects lipid droplets from cAMP-mediated lipolysis [30], thus, an increase in Plin2 expression represents attenuation of lipolytic enzymemediated TG breakdown within the lipid droplet. Those scenarios also would allow for blood LCFA derived from adipose tissue lipolysis to be esterified into TG within liver. Our results support the hypothesis from studies feeding much higher doses of trans-10, cis-12-CLA that hepatic lipogenesis and esterification are primary factors responsible for liver TG accumulation [5, 21, 22].
4.3. Trans-10, cis-12-CLA Increases VLDL Assembly and Secretion. In the liver, synthesized TG is either stored in cytoplasmic droplets or secreted as VLDL particles [31]. Most de novo-synthesized TG is stored in cytosolic TG pools and a smaller portion is secreted in the form of VLDL. Apoprotein B 100 (Apob) is the key component whose rate of synthesis in the rough endoplasmic reticulum controls the overall rate of VLDL production [32]. Lipid components are added to apoprotein B by microsomal TG transfer protein (Mttp). Because Mttp catalyzes the transfer of lipids to the ApoB molecule, Mttp may play a crucial role in the overall assembly and secretion of VLDL in the liver. In addition to these proteins, recent work has uncovered a potentially important function for the cell death-inducing DFF45-like effector (Cide) isoform $b$ (Cideb) protein in the process of VLDL synthesis, for example, liver of Cideb-null mice had higher levels of cytosolic TG accompanied by lower levels of VLDL secretion [33]. Cideb is localized to smooth ER and LD and interacts physically with ApoB [33].

Despite the well-described accumulation of TG in the liver due to CLA (Table 1), which leads to greater tissue mass and greater LCFA (Tables 2 and 3), our results suggested that the VLDL assembly/secretion mechanism in mice fed trans10, cis-12-CLA was not impaired and may have actually been enhanced via the upregulation of hepatic Mttp and Cideb. It was reported previously that in trans-10, cis-12-CLAfed mice the VLDL secretion rate was increased; whereas, the plasma TG concentration was decreased [12]. Taken together, results suggest that the enhanced VLDL secretion rate is insufficient to eliminate excess fatty acids (Table 2 ) entering the esterification and VLDL assembly/secretion pathways resulted from increased fatty acid uptake, which would account for part of the fat deposited within liver cells. Our finding with Mttp is in agreement with recent kinetic studies showing that the actual amount of hepatic TG-rich lipoprotein secretion rate during nonalcoholic fatty liver disease is actually increased, but it is inadequate to match the increased TG synthesis in the liver [34]. The fact that Cideb requires both its ApoB-binding and $\mathrm{LD}$ association domains to allow for secretion of TG-enriched VLDL particles seems to support our findings, that is, Cideb also is required to promote the formation of TG-enriched VLDL particles [33].

4.4. Transcription Regulation and Lipogenesis and TG Synthesis. Sterol regulatory element binding transcription factor 1 (Srebf1) is the key transcription factor regulating hepatic lipogenesis in rodents [35]. Its upregulation with CLA is in agreement with the data on lipogenic genes from the current study as well as previous reports on mice fed higher levels of CLA-mixtures [5]. It is unclear, however, what signal might have triggered upregulation of Srebf1 in our study, but insulin may have played a role. In freshly isolated hepatocytes, Srebf1 mRNA was activated by insulin [36]. Thus, if feeding CLA in our study resulted in greater blood insulin, as previously reported $[5,9]$, it would explain the upregulation of Srebf1. The coordinated greater expression of the Srebf1 target genes Acaca, Scd, and Gpam in mice fed trans-10, cis-12CLA suggested that the liver was generating more palmitic acid and oleic acid (see Table 3 ) and esterifying it into TG. 
Collectively, these results indicated that low dietary trans-10, cis-12-CLA stimulated Srebf1 leading to an overall increase in fat accumulation in liver.

4.5. Ppara and Lipid Catabolism due to trans-10, cis12 CLA. Isomers of CLA have some structural features similar to peroxisome proliferators and, importantly, the physiological responses observed in mice fed high doses of CLA (e.g., reduced body mass, hepatic lipid accumulation, hypolipidemia) are characteristic of this group of chemicals [37]. The ligand-activated transcription factor peroxisome proliferator-activated receptor $\alpha$ (Ppara) modulates lipid catabolism partly via activation of Lpl [37], Acoxl [38], Cpt1a, thioesterases, fatty acid binding protein, peroxisomal and mitochondrial $\beta$ oxidation enzymes, microsomal $\omega$ oxidizing enzymes, and apolipoproteins [35]. Trans-10, cis12-CLA has been reported to be a potent ligand of Ppara [37] and, despite the lack of change in Ppara expression, the upregulation of several of its target genes playing important roles in lipid metabolism (Cd36, Pdk4, Acoxl, Ucp2) provided indirect evidence that trans-10, cis-12-CLA might act through Ppara.

Because a decrease in fatty acid oxidation may cause fat accumulation in liver [13], it is intuitive that the mRNA expression of the enzymes related to fatty acid oxidation may be downregulated during liver lipidosis. However, recent investigations of trans-10, cis-12-CLA effects on fatty acid oxidation are controversial. Rasooly et al. [39] found that trans-10, cis-12-CLA supplementation decreased the expression of Cpt1a (-77\%), Acoxl (-50\%), and Ppara (-65\%). However, in the study of Gruffat et al. [19] liver tissue samples of rats incubated with a fatty acid mixture (representative of circulating LCFA) and trans-10, cis-12-CLA or oleate, they found that the rate of CLA, isomer oxidation was $2 \mathrm{X}$ higher than that of oleate. Furthermore, expression of hepatic fatty acid oxidation genes in mice also increased in three studies with mixtures of CLA isomers [21, 22] and in one study with trans-10, cis-12-CLA [13].

Cptla is considered the rate-limiting enzyme for mitochondrial $\beta$ oxidation [39]. Degrace et al. [13] found an increase in the activity of hepatic Cptla in mice supplemented with trans-10, cis-12-CLA accompanied by an increase in Acoxl activity and gene expression. The lack of change in Cptla that we observed with CLA may have been associated with the upregulation of Acaca due to CLA, that is, greater flux through Acaca would have generated malonylCoA which is a potent inhibitor of Cpt1a [32]. Because mice were fed over a 6-week period in the current study, it is possible that adaptive changes occurred wherein the increase in Cpt1a was prevented by the elevated levels of malonylCoA. As a consequence of this effect on Cpt1a, more LCFA would have been available for esterification into TG and accumulation in the cytosol.

In addition to mitochondrial oxidation, peroxisomes also play an important role in LCFA oxidation [32]. Acyl-CoA oxidase 1 (Acox 1$)$ catalyzes the first and rate-limiting enzyme of the peroxisomal fatty acid $\beta$ oxidation pathway [32], and mice lacking Acoxl developed severe steatohepatitis [40]. The upregulation of Acoxl with CLA that we observed suggested an increase in fatty acid $\beta$ oxidation in peroxisomes. The upregulation of Acoxl might have been due to the relatively lower amount of dietary trans-10, cis-12-CLA supplementation compared with previous studies [5, 9-11, 15, 41]. Furthermore, Acox 1 is not affected by malonyl-CoA as Cpt1a and, as such, would represent a mechanism for excess LCFA (e.g., incoming LCFA from adipose catabolism) catabolism to continue on the face of greater lipogenic rates.

Regulation of the pyruvate dehydrogenase complex (PDC) is an important step in fuel selection of energy utilization in animals during different nutritional and hormonal states as the modulation of PDC activity impacts fatty acid as well as pyruvate and glucose metabolism [42]. Phosphorylation of PDC via pyruvate dehydrogenase kinase (Pdk) inhibits its activity [42], thereby reducing the conversion of pyruvate to acetyl-CoA and sparing glucose oxidation in favor of LCFA. The abundance of the Pdk4 isoform, which is highly expressed in liver, heart, and skeletal muscle, is transcriptionally controlled by Pppara [42]. The upregulation of $P d k 4$ with CLA provided evidence of reduced glucose oxidation and supports the view that peroxisomal oxidation of LCFA might have been increased. Because expression of Pdk4 is induced by high-fat diets and LCFA [43], the greater Pdk4 expression was likely a consequence of trans-10, cis-12CLA intake and its catabolic effect on adipose tissue (Tables 1 and 2).

Under conditions of increased fatty acid uptake and oxidation the liver produces large amounts of acetoacetate and D-3-hydroxybutyrate during the process of ketogenesis [32]. Ketogenesis is controlled indirectly by Cptla (i.e., via provision of acetyl-CoA) and directly by the activity of the mitochondrial key regulatory enzyme 3-hydroxy-3-methylglutaryl-CoA synthase 2 (Hmgcs2), which is a Ppara target [44]. The enzyme 3-hydroxybutyrate dehydrogenase 1 (Bdh1) plays a key role in redox balance and energy metabolism since in the presence of NADH, the hepatic Bdh transforms acetoacetate into D-3-hydroxybutyrate, which is then transported through the blood stream to peripheral tissues, for example, brain, heart, and kidney [45]. Our results support previous findings of greater hepatic Hmgcs 2 and Bdh1 expression in mice fed trans-10, cis-12-CLA. Thus, influx of LCFA from adipose lipolysis not only enhanced peroxisomal oxidation but also resulted in increased ketogenesis, which was in agreement with a previous study [46]. Together, data suggested that there was a stimulation of ketone body production in liver due to feeding CLA.

4.6. Trans-10, cis-12-CLA Changes Energy Metabolism in Liver. Uncoupling proteins (Ucp) belong to a family of mitochondrial anion carriers and are present in the mitochondrial inner membrane [47]. Ucp dissipate the proton gradient by allowing the reentry of protons into the mitochondrial matrix during oxidative ATP generation, resulting in the uncoupling of the respiratory chain and heat production [48]. In vivo studies indicated that physiological and pathological elevation of blood LCFA resulting from fasting [49] or high-fat diets [50] induced upregulation of Ucp2. Peters et al. [51] demonstrated that dietary CLA increases Ucp2 expression in murine liver, which we confirmed. The uncoupling 
process might have served as a counterregulatory mechanism to lower cellular ATP levels and decreased metabolic efficiency, thereby serving as a mechanism to reduce fat accumulation in the long term [52].

4.7. Trans-10, cis-12-CLA, and the Stress Response. According to the complex mechanisms proposed by Jaudszus et al. [6], the antiadipogenic effect of trans-10, cis-12-CLA in adipose tissue may be primarily the consequence of proapoptotic and proinflammatory responses, including the nuclear factor $\kappa \mathrm{B}$ $(\mathrm{NF} \kappa \mathrm{B}-)$ dependent production of tumor necrosis factor- $\alpha$, interleukin-6, and interleukin-8 [8, 9]. The lack of alteration in the expression of several genes associated with inflammation or stress response was likely related to the relatively low dosage of trans-10, cis-12-CLA that was fed.

In conclusion, our study showed that even at one of the lowest dietary doses of trans-10, cis-12-CLA studied to date, the coordinated upregulation of genes associated with fatty acid uptake, TG synthesis, and lipid droplet formation as well as insufficient induction of VLDL assembly/secretion contribute to enhanced TG accumulation and greater liver mass. Impaired mitochondrial $\beta$-oxidation did not appear to be a factor contributing to hepatic steatosis, partly due to a greater contribution of the peroxisomal pathway.

\section{Acknowledgments}

Financial support was provided by the University of Illinois Research Board under proposal 07090. S. Viswanadha and J. J. Loor conceived and designed the study. As part of the Ph.D. dissertation, S. Viswanadha coordinated and performed the animal study. As part of the MS thesis, J. J. Loor performed qPCR analysis, conducted statistical analysis, prepared the figures and tables, and wrote the manuscript. J. J. Loor and S. Viswanadha helped wrote the final manuscript. All authors read and approved the final manuscript. There are no financial or other contractual agreements that might cause conflict of interests.

\section{References}

[1] A. Kennedy, K. Martinez, S. Schmidt, S. Mandrup, K. LaPoint, and M. McIntosh, "Antiobesity mechanisms of action of conjugated linoleic acid," Journal of Nutritional Biochemistry, vol. 21, no. 3, pp. 171-179, 2010.

[2] M. Evans, Y. Park, M. Pariza, L. Curtis, B. Kuebler, and M. McIntosh, "Trans-10,cis-12 conjugated linoleic acid reduces triglyceride content while differentially affecting peroxisome proliferator activated receptor $\gamma 2$ and ap2 expression in 3T3L1 preadipocytes," Lipids, vol. 36, no. 11, pp. 1223-1232, 2001.

[3] K. M. Hargrave, C. Li, B. J. Meyer et al., "Adipose depletion and apoptosis induced by trans-10,cis-12 conjugated linoleic acid in mice," Obesity Research, vol. 10, no. 12, pp. 1284-1290, 2002.

[4] T. Tholstrup, M. Raff, E. M. Straarup, P. Lund, S. Basu, and J. M. Bruun, "An oil mixture with trans-10,cis-12 conjugated linoleic acid increases markers of inflammation and in vivo lipid peroxidation compared with cis-9,trans-11 conjugated linoleic acid in postmenopausal women," Journal of Nutrition, vol. 138, no. 8, pp. 1445-1451, 2008.
[5] L. Clément, H. Poirier, I. Niot et al., "Dietary trans-10,cis-12 conjugated linoleic acid induces hyperinsulinemia and fatty liver in the mouse," Journal of Lipid Research, vol. 43, no. 9, pp. 1400-1409, 2002.

[6] A. Jaudszus, P. Moeckel, E. Hamelmann, and G. Jahreis, "Trans-10,cis-12-CLA-caused lipodystrophy is associated with profound changes of fatty acid profiles of liver, white adipose tissue and erythrocytes in mice: possible link to tissue-specific alterations of fatty acid desaturation," Annals of Nutrition and Metabolism, vol. 57, no. 2, pp. 103-111, 2010.

[7] D. S. Kelley, G. L. Bartolini, J. M. Warren, V. A. Simon, B. E. Mackey, and K. L. Erickson, "Contrasting effects of t10,c12and $\mathrm{c} 9, \mathrm{t} 11$-conjugated linoleic acid isomers on the fatty acid profiles of mouse liver lipids," Lipids, vol. 39, no. 2, pp. 135141, 2004.

[8] H. Poirier, J. S. Shapiro, R. J. Kim, and M. A. Lazar, "Nutritional supplementation with trans-10, cis-12-conjugated linoleic acid induces inflammation of white adipose tissue," Diabetes, vol. 55, no. 6, pp. 1634-1641, 2006.

[9] N. Tsuboyama-Kasaoka, M. Takahashi, K. Tanemura et al., "Conjugated linoleic acid supplementation reduces adipose tissue by apoptosis and develops lipodystrophy in mice," Diabetes, vol. 49, no. 9, pp. 1534-1542, 2000.

[10] R. L. House, J. P. Cassady, E. J. Eisen et al., "Functional genomic characterization of delipidation elicited by trans-10, cis12-conjugated linoleic acid (t10c12-CLA) in a polygenic obese line of mice," Physiological Genomics, vol. 21, no. 3, pp. 351361, 2005.

[11] D. S. Kelley, G. L. Bartolini, J. W. Newman, M. Vemuri, and B. E. Mackey, "Fatty acid composition of liver, adipose tissue, spleen, and heart of mice fed diets containing t10, c12-, and c9, t11-conjugated linoleic acid," Prostaglandins Leukotrienes and Essential Fatty Acids, vol. 74, no. 5, pp. 331-338, 2006.

[12] P. Degrace, L. Demizieux, J. Gresti, J. M. Chardigny, J. L. Sébédio, and P. Clouet, "Association of liver steatosis with lipid oversecretion and hypotriglyceridaemia in C57BL/6j mice fed trans-10,cis-12-linoleic acid," The FEBS Letters, vol. 546, no. 2-3, pp. 335-339, 2003.

[13] P. Degrace, L. Demizieux, J. Gresti, J. M. Chardigny, J. L. Sébédio, and P. Clouet, "Hepatic steatosis is not due to impaired fatty acid oxidation capacities in C57BL/6J mice fed the conjugated trans-10,cis-12-isomer of linoleic acid," Journal of Nutrition, vol. 134, no. 4, pp. 861-867, 2004.

[14] N. EFSA Panel on Dietetic Products, and Allergies (NDA), "Scientific Opinion on the safety of "conjugated linoleic acid (CLA)-rich oil" (Tonalin TG 80) as a Novel Food ingredient," EFSA Journal, vol. 8, no. 5, article 1600, 43 pages, 2010.

[15] M. S. Ashwell, R. P. Ceddia, R. L. House et al., "Trans-10, cis12-conjugated linoleic acid alters hepatic gene expression in a polygenic obese line of mice displaying hepatic lipidosis," Journal of Nutritional Biochemistry, vol. 21, no. 9, pp. 848-855, 2010.

[16] A. Aro, S. Männistö, I. Salminen, M. L. Ovaskainen, V. Kataja, and M. Uusitupa, "Inverse association between dietary and serum conjugated linoleic acid and risk of breast cancer in postmenopausal women," Nutrition and Cancer, vol. 38, no. 2, pp. 151-157, 2000.

[17] J. J. Loor, X. Lin, and J. H. Herbein, "Effects of dietary cis 9, trans 11-18:2, trans 10, cis 12-18:2, or vaccenic acid (trans 1118:1) during lactation on body composition, tissue fatty acid profiles, and litter growth in mice," British Journal of Nutrition, vol. 90, no. 6, pp. 1039-1048, 2003.

[18] P. W. Park and R. E. Goins, "In-situ preparation of fatty-acid methyl-esters for analysis of fatty-acid composition in foods," Journal of Food Science, vol. 59, no. 6, pp. 1262-1266, 1994. 
[19] D. Gruffat, A. de la Torre, J. M. Chardigny et al., "In vitro comparison of hepatic metabolism of 9cis-11 trans and 10trans-12cis isomers of CLA in the rat," Lipids, vol. 38, no. 2, pp. 157-163, 2003.

[20] N. Guillén, M. A. Navarro, C. Arnal et al., "Microarray analysis of hepatic gene expression identifies new genes involved in steatotic liver," Physiological Genomics, vol. 37, no. 3, pp. 187$198,2009$.

[21] T. Ide, "Interaction of fish oil and conjugated linoleic acid in affecting hepatic activity of lipogenic enzymes and gene expression in liver and adipose tissue," Diabetes, vol. 54, no. 2, pp. 412-423, 2005.

[22] Y. Takahashi, M. Kushiro, K. Shinohara, and T. Ide, "Activity and mRNA levels of enzymes involved in hepatic fatty acid synthesis and oxidation in mice fed conjugated linoleic acid," Biochimica et Biophysica Acta, vol. 1631, no. 3, pp. 265-273, 2003.

[23] R. A. Coleman and D. P. Lee, "Enzymes of triacylglycerol synthesis and their regulation," Progress in Lipid Research, vol. 43, no. 2, pp. 134-176, 2004.

[24] J. M. Ntambi, "Regulation of stearoyl-CoA desaturase by polyunsaturated fatty acids and cholesterol," Journal of Lipid Research, vol. 40, no. 9, pp. 1549-1558, 1999.

[25] A. Gomez-Munoz, E. H. Hamza, and D. N. Brindley, "Effects of sphingosine, albumin and unsaturated fatty acids on the activation and translocation of phosphatidate phosphohydrolases in rat hepatocytes," Biochimica et Biophysica Acta, vol. 1127, no. 1, pp. 49-56, 1992.

[26] D. Lindén, L. William-Olsson, M. Rhedin, A. K. Asztély, J. C. Clapham, and S. Schreyer, "Overexpression of mitochondrial GPAT in rat hepatocytes leads to decreased fatty acid oxidation and increased glycerolipid biosynthesis," Journal of Lipid Research, vol. 45, no. 7, pp. 1279-1288, 2004.

[27] E. G. Beale, R. E. Hammer, B. Antoine, and C. Forest, "Disregulated glyceroneogenesis: PCK1 as a candidate diabetes and obesity gene," Trends in Endocrinology and Metabolism, vol. 15, no. 3, pp. 129-135, 2004.

[28] P. E. Bickel, J. T. Tansey, and M. A. Welte, "PAT proteins, an ancient family of lipid droplet proteins that regulate cellular lipid stores," Biochimica et Biophysica Acta, vol. 1791, no. 6, pp. 419-440, 2009.

[29] W. Motomura, M. Inoue, T. Ohtake et al., "Up-regulation of ADRP in fatty liver in human and liver steatosis in mice fed with high fat diet," Biochemical and Biophysical Research Communications, vol. 340, no. 4, pp. 1111-1118, 2006.

[30] J. T. Tansey, C. Sztalryd, J. Gruia-Gray et al., "Perilipin ablation results in a lean mouse with aberrant adipocyte lipolysis, enhanced leptin production, and resistance to diet-induced obesity," Proceedings of the National Academy of Sciences of the United States of America, vol. 98, no. 11, pp. 6494-6499, 2001.

[31] T. Yamazaki, E. Sasaki, C. Kakinuma, T. Yano, S. Miura, and O. Ezaki, "Increased very low density lipoprotein secretion and gonadal fat mass in mice overexpressing liver DGAT1," The Journal of Biological Chemistry, vol. 280, no. 22, pp. 2150621514, 2005.

[32] P. Nguyen, V. Leray, M. Diez et al., "Liver lipid metabolism," Journal of Animal Physiology and Animal Nutrition, vol. 92, no. 3, pp. 272-283, 2008.

[33] J. Ye, J. Z. Li, Y. Liu et al., "Cideb, an ER- and lipid dropletassociated protein, mediates VLDL lipidation and maturation by interacting with apolipoprotein B," Cell Metabolism, vol. 9, no. 2, pp. 177-190, 2009.

[34] E. Fabbrini, B. S. Mohammed, F. Magkos, K. M. Korenblat, B. W. Patterson, and S. Klein, "Alterations in adipose tissue and hepatic lipid kinetics in obese men and women with nonalcoholic fatty liver disease," Gastroenterology, vol. 134, no. 2, pp. 424-431, 2008.

[35] B. Desvergne and W. Wahli, "Peroxisome proliferator-activated receptors: nuclear control of metabolism," Endocrine Reviews, vol. 20, no. 5, pp. 649-688, 1999.

[36] M. Foretz, C. Pacot, I. Dugail et al., "ADD1/SREBP-1c is required in the activation of hepatic lipogenic gene expression by glucose," Molecular and Cellular Biology, vol. 19, no. 5, pp. 3760-3768, 1999.

[37] S. Y. Moya-Camarena, J. P. Vanden Heuvel, S. G. Blanchard, L. A. Leesnitzer, and M. A. Belury, "Conjugated linoleic acid is a potent naturally occurring ligand and activator of PPAR $\alpha$," Journal of Lipid Research, vol. 40, no. 8, pp. 1426-1433, 1999.

[38] J. D. Tugwood, I. Issemann, R. G. Anderson, K. R. Bundell, W. L. McPheat, and S. Green, "The mouse peroxisome proliferator activated receptor recognizes a response element in the $5^{\prime}$ flanking sequence of the rat acyl CoA oxidase gene," EMBO Journal, vol. 11, no. 2, pp. 433-439, 1992.

[39] R. Rasooly, D. S. Kelley, J. Greg, and B. E. Mackey, "Dietary trans 10, cis 12-conjugated linoleic acid reduces the expression of fatty acid oxidation and drug detoxification enzymes in mouse liver," British Journal of Nutrition, vol. 97, no. 1, pp. 58-66, 2007.

[40] C. Y. Fan, J. Pan, N. Usuda, A. V. Yeldandi, M. S. Rao, and J. K. Reddy, "Steatohepatitis, spontaneous peroxisome proliferation and liver tumors in mice lacking peroxisomal fatty acyl-CoA oxidase: implications for peroxisome proliferatoractivated receptor $\alpha$ natural ligand metabolism," The Journal of Biological Chemistry, vol. 273, no. 25, pp. 15639-15645, 1998.

[41] Y. Takahashi, M. Kushiro, K. Shinohara, and T. Ide, "Dietary conjugated linoleic acid reduces body fat mass and affects gene expression of proteins regulating energy metabolism in mice," Comparative Biochemistry and Physiology B, vol. 133, no. 3, pp. 395-404, 2002.

[42] R. A. Harris, M. M. Bowker-Kinley, B. Huang, and P. Wu, "Regulation of the activity of the pyruvate dehydrogenase complex," Advances in Enzyme Regulation, vol. 42, pp. 249259, 2002.

[43] M. C. Sugden, K. Bulmer, G. F. Gibbons, B. L. Knight, and M. J. Holness, "Peroxisome-proliferator-activated receptor- $\alpha$ $(\operatorname{PPAR} \alpha)$ deficiency leads to dysregulation of hepatic lipid and carbohydrate metabolism by fatty acids and insulin," Biochemical Journal, vol. 364, no. 2, pp. 361-368, 2002.

[44] F. G. Hegardt, "Mitochondrial 3-hydroxy-3-methylglutarylCoA synthase: a control enzyme in ketogenesis," Biochemical Journal, vol. 338, no. 3, pp. 569-582, 1999.

[45] D. H. Williamson, M. W. Bates, M. A. Page, and H. A. Krebs, "Activities of enzymes involved in acetoacetate utilization in adult mammalian tissues," Biochemical Journal, vol. 121, no. 1, pp. 41-47, 1971.

[46] M. Sakono, F. Miyanaga, S. Kawahara et al., "Dietary conjugated linoleic acid reciprocally modifies ketogenesis and lipid secretion by the rat liver," Lipids, vol. 34, no. 9, pp. 997-1000, 1999.

[47] F. Bouillaud, E. Couplan, C. Pecqueur, and D. Ricquier, "Homologues of the uncoupling protein from brown adipose tissue (UCP1): UCP2, UCP3, BMCP1 and UCP4," Biochimica et Biophysica Acta, vol. 1504, no. 1, pp. 107-119, 2001.

[48] H. Aquila, T. A. Link, and M. Klingenberg, "The uncoupling protein from brown fat mitochondria is related to the mitochondrial ADP/ATP carrier. Analysis of sequence homologies and of folding of the protein in the membrane," $E M B O$ Journal, vol. 4, no. 9, pp. 2369-2376, 1985. 
[49] D. S. Weigle, L. E. Selfridge, M. W. Schwartz et al., "Elevated free fatty acids induce uncoupling protein 3 expression in muscle: a potential explanation for the effect of fasting," Diabetes, vol. 47, no. 2, pp. 298-302, 1998.

[50] C. Fleury, M. Neverova, S. Collins et al., "Uncoupling protein2: a novel gene linked to obesity and hyperinsulinemia," $\mathrm{Na}$ ture Genetics, vol. 15, no. 3, pp. 269-272, 1997.

[51] J. M. Peters, Y. Park, F. J. Gonzalez, and M. W. Pariza, "Influence of conjugated linoleic acid on body composition and target gene expression in peroxisome proliferator-activated receptor $\alpha$-null mice," Biochimica et Biophysica Acta, vol. 1533, no. 3, pp. 233-242, 2001.

[52] J. R. Soh, D. H. Shin, D. Y. Kwon, and Y. S. Cha, "Effect of Cheonggukjang supplementation upon hepatic acyl-CoA synthase, carnitine palmitoyltransferase I, acyl-CoA oxidase and uncoupling protein 2 mRNA levels in C57BL/6J mice fed with high fat diet," Genes and Nutrition, vol. 2, no. 4, pp. 365$369,2008$.

[53] G. V. Halade, M. M. Rahman, and G. Fernandes, "Effect of CLA isomers and their mixture on aging C57Bl/6J mice," European Journal of Nutrition, vol. 48, no. 7, pp. 409-418, 2009.

[54] J. M. Warren, V. A. Simon, G. Bartolini, K. L. Erickson, B. E. Mackey, and D. S. Kelley, "Trans-10,cis-12 CLA increases liver and decreases adipose tissue lipids in mice: possible roles of specific lipid metabolism genes," Lipids, vol. 38, no. 5, pp. 497504, 2003. 

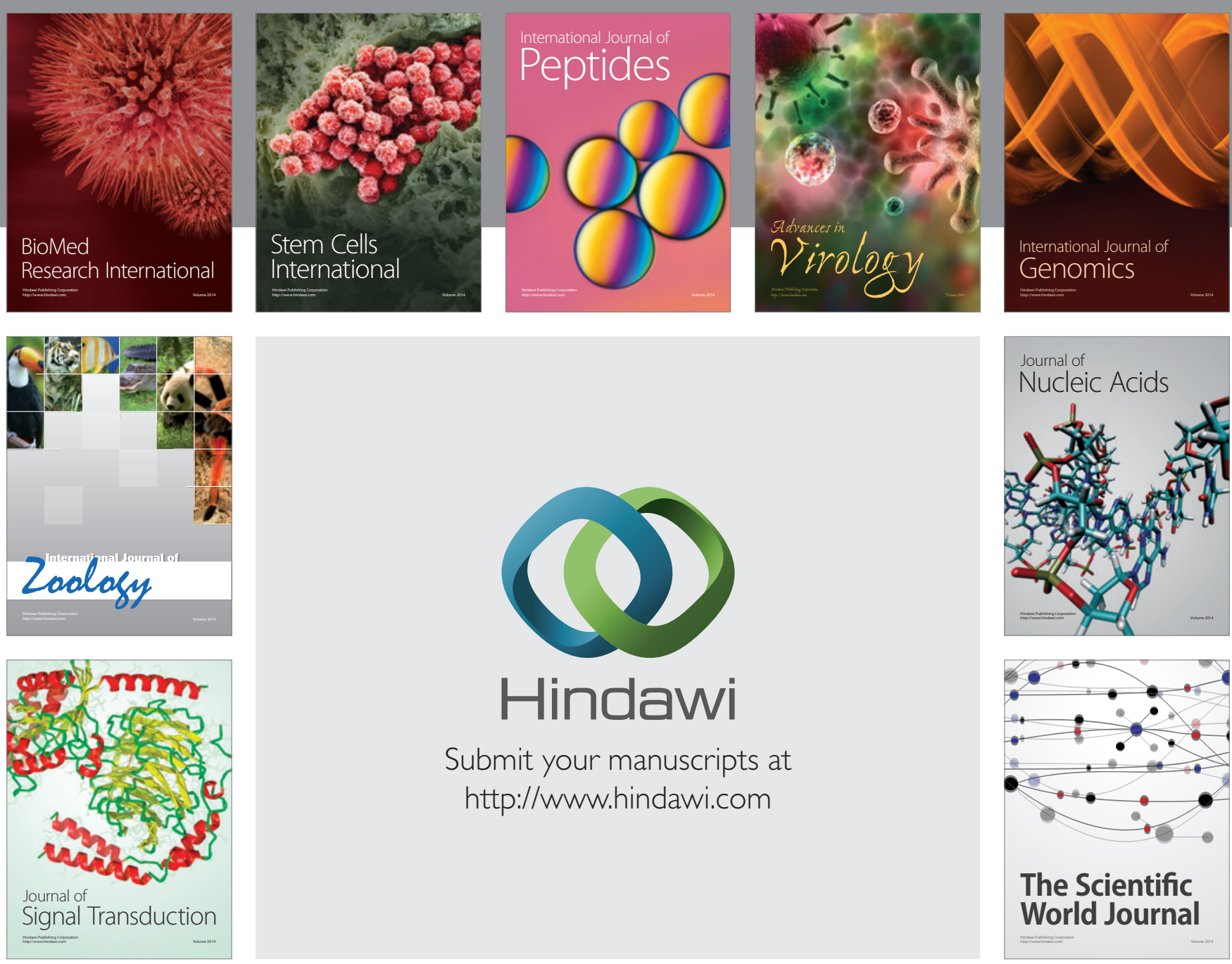

Submit your manuscripts at

http://www.hindawi.com
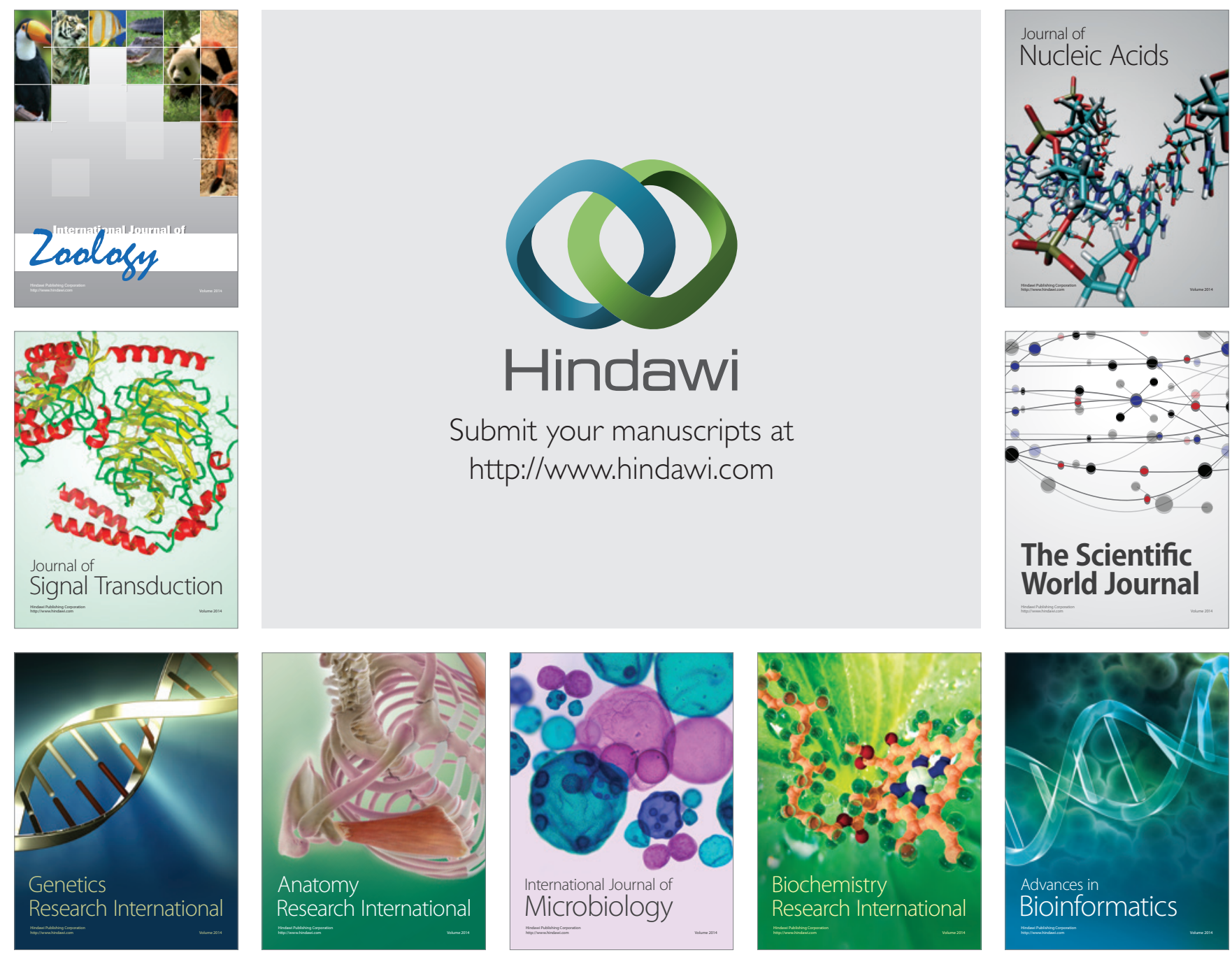

The Scientific World Journal
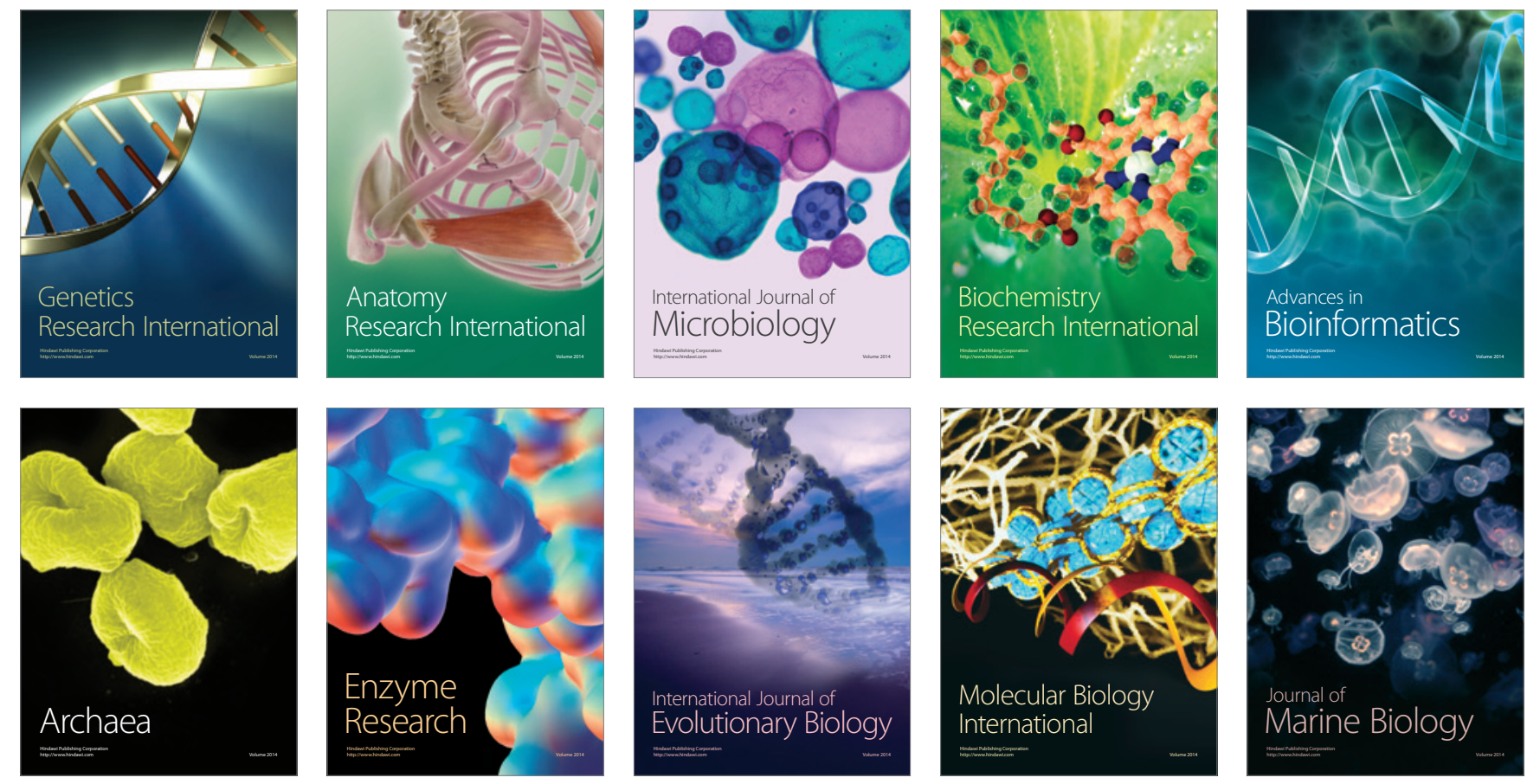